D) Check for updates

Cite this as: $B M J 2021 ; 373: n 1326$ http://dx.doi.org/10.1136/bmj.n1326 Published: 24 May 2021

\section{Newer drug treatments for type 2 diabetes}

In this editorial by Guo and Smith (BMJ 2021;373:n1171, doi:, published 11 May 2021), the second sentence should have stated: "diabetes causes 1.5 million deaths annually" [not daily]. The article has now been corrected. 